\title{
Predominance of multi-resistant gram-negative bacteria colonizing chronic lower limb ulcers (CLLUs) at Bugando Medical Center
}

\author{
Nyambura Moremi ${ }^{1 \dagger}$, Martha F Mushi ${ }^{1 *}$, Mbunda Fidelis $^{2+}$, Phillipo Chalya ${ }^{2}$, Mariam Mirambo ${ }^{1}$
} and Stephen E Mshana'

\begin{abstract}
Background: Infections, trauma, malignances and poorly controlled diabetes are common causes of chronic lower limb ulcerations in developing countries. Infected wound with multi-drug resistant bacteria usually are associated with increased morbidity and mortality. We report the distribution of bacteria pathogens colonizing the chronic lower limb ulcers and their drug susceptibility pattern from Bugando Medical Centre (BMC) a tertiary hospital in Tanzania.

Findings: Three hundred non-repetitive wound swabs were aseptically collected from 300 patients with chronic lower limb ulcers using sterile swabs and processed following standard operative procedures. Isolates were identified using in house biochemical testing and in case of ambiguous confirmation was done using API 20NE and API 20E. Susceptibility was determined using disc diffusion test following clinical laboratory standard Institute guidelines (CLSI). Of 300 swabs from patients with chronic lower limbs ulcers, 201 (67.7\%) had positive aerobic culture within 48 hours of incubation. Of 201 isolates, 180(89.6\%) were gram-negative bacteria. Out of 180 gram negative bacteria, resistance was detected for ampicillin (95\%, $n=171)$, amoxicillin/clavulanate $(83.9 \%, n=151)$, trimethoprim-sulphamethoxazole $(78.9 \%, n=142)$, ceftriaxone $(46.7 \%, n=84)$, ceftazidime $(45.6 \%, n=82)$, gentamicin $(39.4 \%, n=71)$, ciprofloxacin $(17.8 \%, n=32)$ and meropenem $28(15.6 \%, n=25)$. A total of $41(35 \%)$ of enterobacteriaceae were found to be extended spectrum beta-lactamases (ESBL) producers while of 18 Staphylococcus aureus, 8(44.4\%) were found to be methicillin resistant Staphylococcus aureus (MRSA).
\end{abstract}

Conclusion: There is high prevalence of ESBL and MRSA isolates in surgical wards at BMC. We recommend infection control and antibiotic stewardship programs in these wards to minimize spread of multi-resistant organisms.

Keywords: Chronic lower limb ulcers, Multi-drug resistant, Gram negative enteric

\section{Findings \\ Background}

In developing countries infections, trauma, malignances and poorly controlled diabetes are the most common causes of chronic lower limb ulcerations [1,2]. An infected wound complicates the postoperative course and results in prolonged hospital stay and delayed recovery [3]. Prolonged hospital stay usually exposes the patient to health care associated infections (HCAs) [4], and

\footnotetext{
*Correspondence: marthamushi@yahoo.com

${ }^{\dagger}$ Equal contributors

'Department of Microbiology/Immunology, Catholic University of Health and Allied Sciences, P.O.BOX 1464 Mwanza, Tanzania

Full list of author information is available at the end of the article
}

more risk to infection due multi-drug resistant bacteria like extended spectrum beta lactamase (ESBL) producers and methicillin resistant Staphylococcus aureus (MRSA) [5-8]. In Tanzania about 50\% of Klebsiella pneumonia and $25-45 \%$ of Escherichia coli isolated from HCAIs are reported to be ESBL producers [9-11]. Also in Tanzania S. aureus has been reported to be the commonest cause of surgical site infections of which $18.8 \%$ are reported to be MRSA [3].

Clinical experience and outcome of patients regarding chronic lower limb ulcers in this centre has been described in previous publication [12]. This article is building from the same study but focusing on distribution of

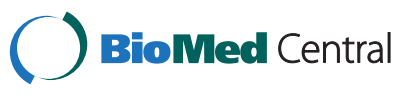


bacteria pathogens, susceptibility pattern of gram negative and gram positive isolates from chronic lower limb ulcers. In addition more information regarding the susceptibility pattern that predicts ESBL phenotype is presented.

The predominance of multi-drug resistant gram negative bacteria colonizing and infecting lower limbs necessitates the scaling up of infection control practices and the introduction of antibiotic stewardship in surgical wards in developing countries.

\section{Methods}

\section{Study population}

A cross sectional study involving all patients with chronic lower limbs ulcers was conducted between November 2011 and February 2012 in surgical wards of Bugando Medical Centre (BMC), a 1000 bed capacity tertiary hospital in the northwestern part of Tanzania as previously described [12].

\section{Laboratory procedures}

A total of 300 non-repetitive wound swabs were collected from 300 patients with chronic lower limb ulcers using sterile swabs. All swabs were processed as previously described [13]. Briefly specimens were inoculated on MacConkey agar and 7\% sheep blood agar (HIMEDIA, INDIA) and incubated at $35^{\circ} \mathrm{C}$ aerobically for 24$48 \mathrm{hrs}$. Identification of bacteria was done using colonies characteristics, hemolysis on blood agar, lactose fermentation on differential media and in house biochemical tests using colonies from pure cultures; in case of ambiguous results confirmation was done using API 20NE and API 20E [11].

\section{Antibacterial susceptibility testing}

Susceptibility testing was performed by Kirby-Bauer technique. The $0.5 \mathrm{McFarland}$ of test organism was uniformly seeded over the Mueller-Hinton agar surface and incubated at $35^{\circ} \mathrm{C}$ for 24 hours. Interpretation was made as per CLSI [14]. Antibiotics discs tested for gram positive bacteria included ampicillin $(10 \mu \mathrm{g})$, cefoxitin $(30 \mu \mathrm{g})$, trimethoprimsulphamethoxazole $(1.25 / 23.75 \mu \mathrm{g})$, gentamicin $(10 \mu \mathrm{g})$, erythromycin $(15 \mu \mathrm{g})$, clindamycin $(2 \mu \mathrm{g})$ and vancomycin $(30 \mu \mathrm{g})$. For gram negative bacteria, disc tested include ceftazidime $(30 \mu \mathrm{g})$, amoxicillin/clavulanate $(20 / 10 \mu \mathrm{g})$, ceftriaxone $(30 \mu \mathrm{g})$, gentamicin $(10 \mu \mathrm{g})$, trimethoprimsulphamethoxazole $(1.25 / 23.75 \mu \mathrm{g})$, ciprofloxacin $(5 \mu \mathrm{g})$, meropenem $(10 \mu \mathrm{g})$ and ampicillin $(10 \mu \mathrm{g})$. ESBL producers were detected using disk approximation method as described previously $[15,16]$ while MRSA were detected using cefoxitin disc $30 \mu \mathrm{g}$, all isolates resistant to $30 \mu \mathrm{g}$ cefoxitin based on CLSI were considered as MRSA [17]. In this study all isolates resistant to at least three of the following antimicrobials: ampicillin, amoxicillin/clavulanate, ceftazidime, ciprofloxacin, gentamicin, and/or trimethoprim-sulphamethoxazole (SXT) were considered as multi-drug resistant bacteria [18].

The study was approved by Bugando Medical Centre/ Catholic University of Health and Allied Sciences ethics committee and the informed consent were obtained from all patients.

\section{Results}

A total of 300 patients with CLLUs were included in the study. Traumatic ulcers were the most frequent type of ulcer accounting for $181(60.3 \%)$ of patients followed by infective ulcers 43 (14.3\%), metabolic ulcers 35 (11.7\%), neoplastic/malignant ulcers 20 (6.7\%), vascular ulcers 11 (3.7\%), neuropathic ulcers $8(2.7 \%)$ and ulcerating skin lesions e.g. pyogenic granulomatous $2(0.7 \%)$. Out of 300, 201 (67\%) had positive aerobic culture within 48 hours of incubation. Of 201 positive cultures 180 (89.6\%) were identified as gram negative bacteria and 21 $(15.9 \%)$ as gram positive bacteria (Staphylococcus aureus 18, Enterococcus spp 3). Bacteria species isolated were; Pseudomonas spp. 54 (26.9\%), Proteus spp. 45 (22.4\%), Klebsiella pneumoniae 33 (16.4\%), E. coli 26 (12.9\%), Staphylococcus aureus 18 (9\%), Acinetobacter spp. 9 (4.5\%), Serratia spp. 7 (3.5\%), Enterobacter spp. 6 (3\%) and Enterococcus spp 3 (1.5\%).

Of 180 gram negative bacteria, resistance was detected for ampicillin (95\%, $\mathrm{n}=171)$, amoxicillin/clavulanate $(83.9 \%$, $\mathrm{n}=151)$, trimethoprim-sulphamethoxazole $(78.9 \%, \mathrm{n}=142)$, ceftriaxone $(46.7 \%, \mathrm{n}=84)$, ceftazidime $(45.6 \%, \mathrm{n}=82)$,

Table 1 Resistance pattern of $\mathbf{1 8 0}$ gram negative isolates to various antibiotics in percentage

\begin{tabular}{lccccccccc}
\hline Bacteria isolates & N & AMP & CAZ & AMC & CRO & GM & SXT & CIP & MEM \\
\hline E.coli & 26 & 100 & 50.0 & 88.5 & 50.0 & 30.8 & 76.9 & 19.2 & 19.2 \\
Klebsiella spp. & 33 & 100 & 59.4 & 93.9 & 59.3 & 54.5 & 78.8 & 9.1 & 6.06 \\
Pseudomonas spp. & 54 & 100 & 55.1 & 92.6 & 55.1 & 44.4 & 96.3 & 20.4 & 25.9 \\
Proteus spp. & 45 & 88.9 & 20.0 & 71.1 & 20.0 & 22.2 & 57.8 & 17.8 & 2.2 \\
*Other gm-ve spp & 22 & 80.0 & 45.9 & 68.0 & 54.5 & 52.0 & 84.0 & 24.0 & 28.0 \\
Total & 180 & 95 & 45.6 & 83.9 & 46.7 & 39.4 & 78.9 & 17.8 & 15.6 \\
\hline
\end{tabular}

Keys: AMP = Ampicillin, CAZ = Ceftazidime, AMC = Augmentin, CRO = Ceftriaxone GM = Gentamicin, SXT = trimethoprim-sulphamethoxazole, CIP = Ciprofloxacin, $\mathrm{MEM}=$ Meropenem. ${ }^{*}$ Acinetobacter spp., Serratia spp. and Enterobacter spp. 
gentamicin $(39.4 \%, \mathrm{n}=71)$, ciprofloxacin $(17.8 \%, \mathrm{n}=32)$ and meropenem $28(15.6 \%, \mathrm{n}=25)$ Table 1 . A total of 41 (35\%) of enterobacteriaceae were found to be ESBL producers, with specific ESBL rate for Escherichia coli and Klebsiella spp being 50\% and 53\% respectively. The resistance to trimethoprim-sulphamethoxazole, gentamicin and ciprofloxacin was found to predict ESBL phenotype (Table 2). Staphylococcus aureus were resistant to penicillin (79.3\%), amoxicillin/clavulanate $(60 \%)$, gentamicin (8.3\%), trimethoprim-sulphamethoxazole (60\%), clindamycin (20.7\%), erythromycin (13.8\%) and 8 (44.4\%) were found to be MRSA.

\section{Discussion}

The microbiological profile of chronic ulcers of the lower limbs is very important in the provision of appropriate management of ulcers as well as institution-specific antibiotic policy in the surgical wards [19]. As reported previously [3], Pseudomonas aeruginosa was the most frequent gram negative bacteria isolated while Staphylococcus aureus was the commonest gram positive bacteria. Most of these isolates were multiply-resistant to commonly used antibiotics. This is due to the fact that most of these patients were hospitalized for more than 72 hrs signifying health care associated infections [3].
Compared to previous data in the surgical wards [3] the ESBL rates among Klebsiella spp and E. coli colonizing CLLU were lower than those involved in surgical site infections. Also this study confirmed the previous observation $[10,11]$ that the resistance to trimethoprim-sulphamethoxazole, gentamicin, and ciprofloxacin is a predictor of ESBL phenotype. Most of ESBL producers in this study are multi-drug resistance, due to the fact that most of ESBL conjugative plasmids observed previously in this settings [20,21] carry resistance markers for other antibiotic classes such as tetracycline, gentamicin and trimethoprim-sulphamethoxazole. Similar to other studies [11,22], majority of gram negative and gram positive isolates were sensitive to meropenem and vancomycin respectively. Increased trend was observed for MRSA at BMC whereby in 2009 and 2011 about 16.3\% and $18.8 \%$ of $S$. aureus were found to be MRSA respectively $[3,17]$ while in the current study about $44 \%$ of Staphylococcus aureus were found to be MRSA.

Despite the importance of these data some limitations were failure to perform; anaerobic culture, molecular characterization and PCR confirmation of ESBL and MRSA phenotype.

\section{Conclusion}

High prevalence of ESBL and MRSA isolates were observed in surgical wards at BMC. We highly recommend Infection

Table 2 Antimicrobial resistance pattern that predict ESBL phenotype

\begin{tabular}{|c|c|c|c|c|}
\hline \multirow{2}{*}{$\begin{array}{l}\text { Predictive drug } \\
\text { resistance phenotype }\end{array}$} & \multicolumn{2}{|c|}{ ESBL n (\%) } & \multirow[t]{2}{*}{ OR (95\% Cl) } & \multirow[t]{2}{*}{$p$-value } \\
\hline & Yes & No & & \\
\hline \multicolumn{5}{|l|}{ AAGCS } \\
\hline Yes & $12(44.4)$ & 15 (55.6) & $3.50(1.5-8.3)$ & 0.004 \\
\hline No & $29(18.6)$ & $127(81.4)$ & 1 & \\
\hline \multicolumn{5}{|l|}{ AAG } \\
\hline Yes & $30(44.8)$ & 37 (55.2) & $7.74(3.5-17.0)$ & $<0.001$ \\
\hline No & $11(9.48)$ & 105 (90.5) & 1 & \\
\hline \multicolumn{5}{|l|}{ AAC } \\
\hline Yes & $14(43.8)$ & $18(56.3)$ & $3.57(1.6-8.1)$ & 0.002 \\
\hline No & $27(17.9)$ & $124(82.1)$ & 1 & \\
\hline \multicolumn{5}{|l|}{ GCS } \\
\hline Yes & $12(42.9)$ & $16(57.1)$ & $3.26(1.4-7.6)$ & 0.006 \\
\hline No & $29(18.7)$ & $126(81.3)$ & 1 & \\
\hline \multicolumn{5}{|l|}{ GC } \\
\hline Yes & $12(42.9)$ & $16(57.1)$ & $3.26(1.4-7.6)$ & 0.006 \\
\hline No & $29(18.7)$ & $126(81.3)$ & 1 & \\
\hline \multicolumn{5}{|l|}{ GS } \\
\hline Yes & $33(45.8)$ & $39(54.2)$ & $10.89(4.6-25.6)$ & $<0.001$ \\
\hline No & $8(7.2)$ & 103 (92.8) & 1 & \\
\hline
\end{tabular}

Note: AAGCS = A- Ampicillin, A- Amoxicillin/Clavulanate, G- Gentamicin, C-Ciprofloxacin, and S- trimethoprim-sulphamethoxazole, AAG = A- Ampicillin, A- Augmentin, G- Gentamicin, AAC = A- Ampicillin, A-Augmentin, C-Ciprofloxacin, GCS = G- Gentamicin, C-Ciprofloxacin, S- trimethoprim-sulphamethoxazole, GC = G- Gentamicin, C- Ciprofloxacin, GS = G- Gentamicin, S- trimethoprim-sulphamethoxazole. 
control and antibiotic stewardship programs in these wards to minimize spread of multi-resistant organisms. Coordinated surveillance of multi drug resistant isolates in Tanzania and other developing countries is highly needed so that this worldwide public health problem is controlled.

\section{Competing interests}

The authors declare that they have no competing interests.

\section{Authors' contributions}

MFM, NM, SEM participated in the design of the work, data analysis and interpretation of the results; FM, PC collected specimens; MFM, MM and SEM prepared the first draft of the manuscript; all authors read and approved the final manuscript.

\section{Acknowledgements}

We would like to acknowledge the assistance and guidance provided by all staff members of the department of Surgery, Bugando Medical Center and Microbiology/Immunology, Catholic University of Health and Allied Sciences, Bugando. This study was supported by reagents to SEM from SACIDS.

\section{Author details}

${ }^{1}$ Department of Microbiology/Immunology, Catholic University of Health and Allied Sciences, P.O.BOX 1464 Mwanza, Tanzania. ${ }^{2}$ Department of Surgery, Catholic University of Health and Allied Sciences, P.O.BOX 1464 Mwanza, Tanzania.

Received: 18 September 2013 Accepted: 1 April 2014 Published: 4 April 2014

\section{References}

1. Margolis D, Bilker W, Santanna J, Baumgarten M: Venous leg ulcer: incidence and prevalence in the elderly. J Am Acad Dermatol 2002 46:381-386

2. Liedberg $E$, Persson B: Increased incidence of lower limb amputation for arterial occlusive disease. Acta Orthop Scand 1983, 54:230-234.

3. Mawalla B, Mshana SE, Chalya PL, Imirzalioglu C, Mahalu W: Predictors of surgical site infections among patients undergoing major surgery at Bugando Medical Centre in Northwestern Tanzania. BMC Surg 2011, 11(1):21.

4. Green JW, Wenzel RP: Postoperative wound infection: a controlled study of the increased duration of hospital stay and direct cost of hospitalization. Ann Surg 1977, 185(3):264-268.

5. Knothe $H$, Shah $P$, Krcmery $V$, Antal M, Mitsuhashi S: Transferable resistance to cefotaxime, cefoxitin, cefamandole and cefuroxime in clinical isolates of Klebsiella pneumoniae and Serratia arcescens. Infection Nov-Dec 1983, 11(6):315-317.

6. Noyal MJC, Menezes GA, Harish BN, Sujatha S, Parija SC: Simple screening tests for detection of carbapenemases in clinical isolates of nonfermentative Gram-negative bacteria. Indian J Med 2009, 129:707-712.

7. Moquet O, Bouchiat C, Kinana A, Seck A, Arouna O, Bercion R, Breurec S, Garin B: Class D OXA-48 carbapenemase in multidrug-resistant enterobacteria, Senegal. Emerg Infect Dis 2011, 17:143-144.

8. Alebachew T, Yismaw G, Derabe A, Sisay Z: Staphylococcus aureus burn wound infection among patients attending Yeketit 12 hospital burn unit, Addis Ababa, Ethiopia. Ethiop J Health Sci 2012, 22:3.

9. Kayange N, Kamugisha E, Jeremiah S, Mwizamholya DL, Mshana SE: Predictors of positive blood culture and deaths among neonates with suspected neonatal sepsis in a tertiary hospital, Mwanza- Tanzania. BMC Pediatr 2010, 10:39.

10. Moyo J, Aboud S, Kasubi M, Lyamuya EF, Maselle SY: Antimicrobial resistance among producers and non-producers of extended spectrum betalactamases in urinary isolates at a tertiary Hospital in Tanzania. BMC Research Notes 2010, 3:348.

11. Mshana SE, Kamugisha E, Mirambo M, Chakraborty T, Lyamuya E: Prevalence of multiresistant Gram-negative organisms in a tertiary hospital in Mwanza, Tanzania. BMC Research Notes 2009, 2:49.
12. Mbunda F, Mchembe MD, Chalya PL, Rambau P, Mshana SE, Kidenya BR, Gilyoma JM: Experiences with surgical treatment of chronic lower limb ulcers at a tertiary hospital in northwestern Tanzania: a prospective review of 300 cases. BMC Dermatol 2012, 12(1):17.

13. Cheesbough M: District Laboratory Practice in Tropical Countries Part 2 second edition, vol. part 2. Cambrige University Press; 2006.

14. Clinical and Laboratory Standards institute: Performance Standard for Antimicrobial Susceptibility Testing 20 ${ }^{\text {th }}$ Informational Suplliment vol. 30; 2010.

15. M'Zali F, Chanawong A, Kerr K, Birkenhead D, Hawley P: Detection of extendedspectrum beta-lactamases in members of the family Enterobacteriaceae: comparison of the Mast DD test, the double disc and the E-test ESBL. Antimicrob Agent Chemother 2000, 45:881-885.

16. Gheldre $Y$, Avesami V, Berhin C, Delmee M, Glupenzynskii Y: Evaluation of OXOID combinations disc for detection of extended $\beta$-Lactamases. J Antimicrob Chemother 2003, 52:591-597.

17. Mshana S, Kamugisha E, Mirambo M, Chalya P, Rambau P, Mahalu W, Lyamuya E: Prevalence of clindamycin inducible resistance among methicillin-resistant Staphylococcus aureus at Bugando Medical Centre, Mwanza, Tanzania. Tanzania J Health Res 2009, 11:2.

18. Mushi MF, Mshana SE, Imirzalioglu C, Bwanga F: Carbapenemase genes among multidrug resistant gram negative clinical isolates from a tertiary hospital in Mwanza, Tanzania. BioMed Res Int 2014, 2014.

19. Lim TS, Bibombe PM, Ronan M, Kishore S, Manzoor A, Donna A: Microbiological profile of chronic ulcers of the lower limb: A prospective observational study cohort study. ANZ J Surg 2006, 76(8):688-692.

20. Mshana S, Imirzalioglu C, Hain T, Domann E, Lyamuya E, Chakraborty T: Multiple ST clonal complexes, with a predominance of ST131, of Escherichia coli harbouring blaCTX-M-15 in a tertiary hospital in Tanzania. Clin Micro Infect 2011, 17(8):1279-1282.

21. Mshana SE, Hain T, Domann E, Lyamuya EF, Chakraborty T, Imirzalioglu C: Predominance of Klebsiella pneumoniae ST14 carrying CTX-M-15 causing neonatal sepsis in Tanzania. BMC Infect Dis 2013, 13(1):466.

22. Seni J, Najjuka CF, Kateete DP, Makobore P, Joloba ML, Kajumbula H, Kapesa A, Bwanga F: Antimicrobial resistance in hospitalized surgical patients: a silently emerging public health concern in Uganda. BMC Research Notes 2013, 6(1):298

\section{doi:10.1186/1756-0500-7-211}

Cite this article as: Moremi et al: Predominance of multi-resistant gram-negative bacteria colonizing chronic lower limb ulcers (CLLUs) at Bugando Medical Center. BMC Research Notes 2014 7:211.

\section{Submit your next manuscript to BioMed Central and take full advantage of:}

- Convenient online submission

- Thorough peer review

- No space constraints or color figure charges

- Immediate publication on acceptance

- Inclusion in PubMed, CAS, Scopus and Google Scholar

- Research which is freely available for redistribution
C Biomed Central 